\title{
Analyzing User Involvement Practice: A Case Study
}

\author{
Dr Asaad Alzayed, Dr. Abdulwahed Khalfan \\ Computer Science Department, Public Authority for Applied Education and Training (PAAET), Kuwait
}

\begin{abstract}
Engaging users in software development is recognized as effective in furthering the likelihood of product efficacy and a successful project, together with user contentment. Furthermore, user involvement is potentially applicable to numerous organizational contexts that can incorporate a focused user-centered group. This research analyzes the findings of a case study carried out to assess the user involvement situation within a business specializing in innovative software for general consumers, service providers, and enterprises. This company has now formed a user experience group that is devoted to applying user-centered approaches for the overall development of the organizational structure. General feedback was confirmed as the most typical means of gaining user insight, with the level of user involvement in focused development falling short. Nevertheless, the study led to recognition that a firm plan for drawing users into development processes is necessary moving forward.
\end{abstract}

Keywords-User involvement practices; user involvement challenges; usability; user-center practice; user feedback; end users communication

\section{INTRODUCTION}

Having users participate in software development is a vital hurdle to overcome but problematic to achieve. While developers are always inventing and releasing new, fancy features, they can easily overlook that their key focus needs to be on the quality of end-user experience [1]. Businesses are accustomed to incorporating new features that improve their products, but comprehending the processes their customers benefit from should in fact be their primary concern [2]. Indeed, while customers tend to be seen as the crucial factor for the cash flow their role creates, system users themselves need to also be viewed as vital, considering that the issues they face with securing smooth processes can have a profound knock-on effect on the subsequent engagement and costeffectiveness [3]. The most difficult problem in the software development process is to understand users' needs and priorities; therefore, issues that need to be overcome and the applicability of updates are essential attributes for furthering the ultimate value a customer base will then receive. To help developers gain a better understanding of user requirements, getting those same users to be involved throughout the development process is seen as crucial for securing overall system functionality and user satisfaction [4]. User participation may also help to improve customer loyalty and sustain long connections with users [5-7]. In summary, figuring out how to answer the various user issues can result in a more profitable business, so should not be considered an inferior priority.

There are several approaches to involving users in the developmental contexts. However, going to the extent of challenging users to produce their own applications has met with little success; indeed, it resulted in a lack of understanding between departments, although user productivity has been increased in such a manner [8]. Other approaches have also focused on having users take a planning and coordination approach to developers' workloads [9], together with occupying managerial positions in terms of adopting and implementing new IT innovations [10,11].

Getting users to closely engage with various levels of development can appear to be an inviting approach. In reality, however, it comes with many potential problems and pitfalls. Specific roles, for example, can become obscured, depending on how the user is linked with other departments [12]. Users can be both hostages and propagandists - both of which undermine the ultimate design goals. Hostage users tend to find their efforts blocked from within the design team of which they are supposed to be an important part. On the other hand, propagandists are redirected into developmental training as a result of failing to have a telling impact, but this only means their perspective is no longer relevant as users. Plus, users' involvement in developmental efforts offers no certainty that the actual system design will benefit from their presence, as developers may still overlook them [7,13]. Agile methodologieshave been embraced to increase the potential of users' and customers' participation by putting them into the same area as developers, but it remains problematic to take developers' focus away from software functions, even when they are working closely with users [14].

To address these issues, the aim is to establish effective and reliable methods for incorporating users' perspectives and skills into development processes, which must be adapted to the unique company setting, as well as the departments and functions in question. So, taking marketing as an example, users will tend to be involved in research and assessment above all else, whereas product management will be more closelyconcerned with usability and performance [15].

This research explores the findings of an analysis of how user involvement practice is currently progressing in a business with a key focus on software solutions for various service suppliers and businesses, as well as consumers. Through assessing the means by which the varying activities of a company draw users into their everyday itineraries, together with analyzing how much information they already have on the users, we can aim for productive and in-depth observations on how effective user involvement methods have been. Ideally, we aim for the observations and insights made to serve as advice for professionals and organizations looking to make the most of user involvement moving forward.

The paper consists of five sections. Section 2 presents a literature review to analyze the concept of user involvement in greater depth, informed by available research. Section 3 
covers the research methodology, interviewee backgrounds, and the organization under scrutiny. Section 4 then deals with the various case study outcomes, before Section 5 brings all this together with discussion and conclusions, backed up by research comparisons, and provides suggestions for ongoing research initiatives.

\section{LITERATURE REVIEW}

\section{A. User Involvement}

User involvement is a crucial aspect of developing any robust software. If developers continue to be unaware of the specific needs of their users, this will result in inaccurate assumptions and potentially disastrous consequences. This is backed by the literature, which shows that involving users early in the development process is effective and influential as the expense involved in making modifications grows throughout system development [16]. It has been found that user engagement and involvement have a beneficial influence on system success $[5,17,18]$. Bano and Zowghi [19] found that the relationship between user involvement and system success is not straightforward and is dependent on a variety of factors and conditions concerning the system development process, including the type and size of organizations and projects, the method of data collection and the phases of the system development life cycle during which data was collected, and user involvement or a participative approach to system development, such as agile, user-centered design (UCD), and participatory design (PD), are widely used. Previous research has indicated that involving users as early as possible in the development process it can be cost effective because it minimizes the expenses associated with the modification and redesigns made later in the software development process [16]. Particularly, research in Participatory Design has resulted in the development of a diverse variety of tools and approaches [20]. As defined in the standard ISO 9241210:2010, [21], in order to fully comprehend end users' needs and requirements and to create a system that meets their job, end users should be participated across the whole development process. There are several issues, nevertheless, when you try to involve users to elicit their requirements and there are many developers also fail to exploit them to their full potential [16]. Many developers are also interested in finding out what the overall role of users should be if they have a say in software development. According to Abelein and Paech (2015) [5], the relevant context factors receive minimal attention. As a result, they requested further empirical study on numerous elements of user participation and involvement. Their research showed that the majority of user involvement and participation occurs during the validation and requirement elicitation phases, with only very few methods focusing on user participation and involvement during the software design and implementation processes, despite the fact that many important decisions are made during these processes. The function of users in design projects is not carefully decided in most companies. As a result, users are confused and believe they lack competence in engaging and running the system usually provided (Damodaran, 1996) [12].

User participation, according to Kujala (2003) [18] and Taha et al., (2013) [22], has a favorable influence on user satisfaction and increases the likelihood of product success. Involving users in product design should benefit developers by reducing product risks, lowering product costs and market failure, and increasing business profit [23,24,25]. Several research have concluded that involving users early in the design process is beneficial. The rationale for this is because users may play an important role in product development by interacting with product developers, who then translate the input into product design specifications [24]. However, direct contact with users does not ensure the success of a new product if the product developers do not understand how to engage users in product development. Many approaches have been tried throughout the years to make the product development process more controllable and effective [22]. However, there are no precise approaches for increasing the success of a new product. Furthermore, most approaches that engage the user in the product development process have not been effectively described and clarified. Traditional approaches are more engineering-driven and mostly connected to the manufacturing phase of the design process, and they are not used correctly or employed at the incorrect point of the design process [26].

Rather than imposing techniques and tools, true user participation and involvement will always require an in-depth awareness of the organization's structure and a comprehensive grasp of local conditions to guide user representations and involvement. Users are sometimes involved as information providers to the project team. Users contribute to such projects but have little impact on important decisions, which is one reason of project and IT development failures to reflect properly for real human and organizational demands [12]. Damodaran (1996) [12], classified several forms of user involvement as 'informative' (users supply or obtain information), 'consultative' (users remark on a specified service or set of facilities), or 'participative' (users impact decisions connected to the whole system). There are several documented benefits to the implementation of user involvement in system design, such as accurate user requirements leading to higher quality systems, eliminating unwanted features, and promoting greater levels of acceptance of the system.

\section{B. The Level to which users are involved}

According to Ives and Olson [27], the level of influence wielded over the final results is related to the extent of user involvement. The extent of user involvement, therefore, depends upon the efficacy of the system, with the following definitions applied to describe the level of contribution:

- No involvement: users are either not asked to get involved orare not keen to provide their expertise.

- Symbolic involvement: users are asked to contribute, buttheir perspective is not actually taken on board.

- Advisory involvement: direction is sought via various meansof feedback.

- Involvement via weak participation: users do offer some expertise but have to sign off responsibility as each stageis complete. 
- Involvement by action: a user is a very active part of the design team, perhaps as an on-site colleague or else as anofficial contact that information is fed through.

- Involvement by strong control: users take a hands-on approach as a result of funding the developments, but also in scenarios where an assessment of the user's overall performance is reliant upon robust and innovativesystem design.

The extent and form of user involvement can be viewed as the two levels upon which the various actions or decisions are understood. Perhaps the only kind of user participation in which it is found that the user has a real influence on results is a participatory role. With approaches that are informative and consultative, user direction is available, but there is no guarantee it will not be ignored or overlooked. A participatory form of role and the extent level of user involvement both strongly imply that the user is a member of the design team; however the form also allows the user to have a voice on developed systems, whilst the level implies that it may change.

As these comparisons show, it is entirely possible for user involvement levels to overlap, though this does not necessarily mean the outcomes will be negative. Such an overview will be applied to ourfindings to inform an empirical approach.

\section{METHODOLOGY}

The authors conducted a qualitative research methodology consisting of a semi-structured interview with open-ended questions to collect the data for this research study. In addition, case study methods were adopted to direct our research practices. Yin [28] defined a case study as an applicable social science discipline, incorporating both organizational and managerial contexts. The use of a case study approach in this case is intended to be illustrative, since the aim is to connect the dynamics of current practice while avoiding any influence on the processes at the research analysis.

\section{A. Research Analysis}

Our research has been carried out by observing a software business company throughout 2020. More than 300 staff are employed by this company, whose core operations focus on software solutions sourced by general consumers, service providers, and also small and medium enterprises. Their structural approach includes having a designated user experience team, which is tasked with achieving robust usercentered practices and services for the complete company operations. However, prior to research taking place, this team had only been operational for three months. Part of the research goals, therefore, was to allow the user experience team to gain a firm overview of the situation concerning user involvement practice throughout the various departments, so they could respond by upgrading their activities to suit applicable challenges and goals.

\section{B. Data Collection and Analysis}

We performed 6 face-to-face semi-structured interviews with open-ended questions, each lasting approximately 30-60 minutes. All interview questions were asked in English, but the interviewees were given the right to answer the questions in English or Arabic. To reflect the diverse functional responsibilities, case study participants were selected from a variety of departments (details in Table I). The participants were then asked to reply and explain while commenting on their experiences by explaining the scenarios they faced in the context of user participation in their presently ongoing or recently completed projects. Upon completion of the interviews, a professional transcription service was applied to transcribe all interview recordings in order to extract the essential information from the recordings. Both authors were present at all interviews and made field notes as needed. The field notes and incomplete transcripts were then categorized and thematically evaluated. The data from the interviews was subjected to thematic analysis in the form of template analysis. Template analysis is ideal for comparing the views of various groups within a given setting [29]. Template analysis allows forthe creation of conceptual themes that fit under bordered groupings, ultimately allowing for the identifying of master themes and their subordinate component themes.

TABLE I. ROLES AND FUNCTIONS OF CASE STUDY INFORMANTS

\begin{tabular}{|l|l|l|}
\hline No. & Role & Function \\
\hline 1 & Project Manager & Customer Involvement \\
\hline 2 & Marketing Manager & Marketing \\
\hline 3 & Product Manager & Product Manager \\
\hline 4 & Technical Writer & Localization \& Documentation \\
\hline 5 & Software Architect & Research \& Development \\
\hline 6 & Software Engineering & Research \& Development \\
\hline
\end{tabular}

\section{RESEARCH RESULTS}

The case study results are presented in this section. The user groups indicated by the participants show how the employees tasked with various organizational functions recognize the company's end users as the crucial stakeholders. The information gathered highlights the extent to which end users are understood, together with the means by which such insight has been obtained. We then move on to describe the internal communication networks in place, before indicating work practices that already draw users into system development. Lastly, we focus on the most important hurdles to overcome in order to enhance the user involvement performance.

\section{A. Identified user Groups}

To start with, participants were requested to provide various personal background info, together with their working priorities, and particular projects or products they had expertise in. Then questions moved on to the user groups who benefitted from their various projects and products - covered in Table II. In doing so, all participants identified home users and service providers as the two key user groups. Two interviewees identified both corporate and administrator groups, with the remaining groups all identified by one source only. 
TABLE II. IDENTIFIED USER GROUPS

\begin{tabular}{|l|l|}
\hline User Group & No. \\
\hline Service provider & 6 \\
\hline Home User & 7 \\
\hline Administrator & 3 \\
\hline Corporate Employee & 2 \\
\hline Consumer & 2 \\
\hline Corporate & 2 \\
\hline Mobile User & 2 \\
\hline Partner & 1 \\
\hline Internal Customer & 2 \\
\hline Wholesaler & 3 \\
\hline
\end{tabular}

This broad selection of different user groups is in some part due to the situation of the various departments - in some cases different employees - utilizing different terminology. For example, product management, which appeared to have closer end-user involvement than other departments, used both 'consumer' and 'partner' to indicate either home user or service provider. Other interviewees employed different definitions, using 'partner' to describe both service providers and corporate clients. Furthermore, studying Table II also makes it clear that, as well as using varying terminology, user groups themselves were also understood in different contexts. Some responses, for example, indicated a complete service provider as an end user, while others recognized that any company will have different levels operating within, with the customerinvolvement employee being one such example.

\section{B. User Data Types}

User data is used in this study to refer to any information gathered directly from users, including their needs, challenges they must overcome, and the specific activitiesto which their responsibilities are applicable. The participants' responses show how the various departments view and understand company operations, together with the reasons for why they have come to understand operations insuch a way.

User response for product previously received and used, along with feedback from a trial test before to release of the product, were the most common sort of data source. The majority of employees were found to be sharing information well, although there were also signs of information being kept within specific teams. Support allows key user data feedback from products in use to be accessed, while customer involvement allows for tryout stage feedback to be readily available. See Table III for the complete lists of user data as expressed by the various departments.

Customer involvement feedback is available via tryout testing that is carried out by focused testers looking to identify specific problems with a product. While products are still in their pre-testing phase, small issues can be ironed out, while bigger problems that don't offer a simple fix are scheduled for future product development and upgrades.

Aside from these two types of feedback, product management focuses on collecting vital insights through interaction with end users, which is regarded critical for product concept and definition. Semi-structured interviews, which often include open-ended questions, are the most commonly utilized technique for gathering this information.

\section{User Data Distribution}

Fig. 1 depicts the spread of user Data throughout the company. As the two primary data sources, support and customer participation, their combined feedback is delivered to the majority of other departments. Feedback from support is sent to all structural levels, while the tryout testing before releasing the product undertaken by customer participation is drawn upon to inform product management, research and development, localization and document. The information is particularly vital to product management, who draw feedback from all structural levels to inform their designs and also to pass on key details to other contributors. In terms of getting a product from concept to production, adhering to a common vision is the primary driver of user data.

The two key avenues of product management information are the information each employee has at their disposal and the customer, which is unlike other departments that sometimes rely on less-specific information. Plus, the overall product vision is not necessarily bought into by all the managers involved. However, if a team agrees on a product view, the information is preserved on an official site. When a product is at its conceptual stage, numerous incentives will be stimulated as research and development goals are realized. Crucially, if some of these goals are considered low-level at an early stage, then any correspondence on them will be restricted rather than risk compromising a grander vision. Typically, this vision will be summarized as part of a product vision document.

Key data are supplied by support to other departments in the shape of reports. Participants from localization and document confirmed that such reports could only be accessed via the support function, with the exception of some random examples. The majority of functions $\log$ the reports on specialized network drives, upon which they can be difficult to locate. Customer involvement shares tryout- stage feedback concerning product performance, typically as reports. The employees overseeing this task aim to gain a user's role perspective so they can make clear judgments on what corporate partners require and how end users can benefit. Frequent meetings take place between customer involvement and research and development to assess the latest tryout test feedback.

TABLE III. USER DATA TYPES

\begin{tabular}{|l|l|}
\hline Data & No. \\
\hline Feedback from End User & 8 \\
\hline Feature Request & 2 \\
\hline Tryout Feedback & 7 \\
\hline Usability Problems & 2 \\
\hline Wholesaler Profile & 1 \\
\hline Vision Document & 2 \\
\hline Conceptual Requirement & 1 \\
\hline
\end{tabular}




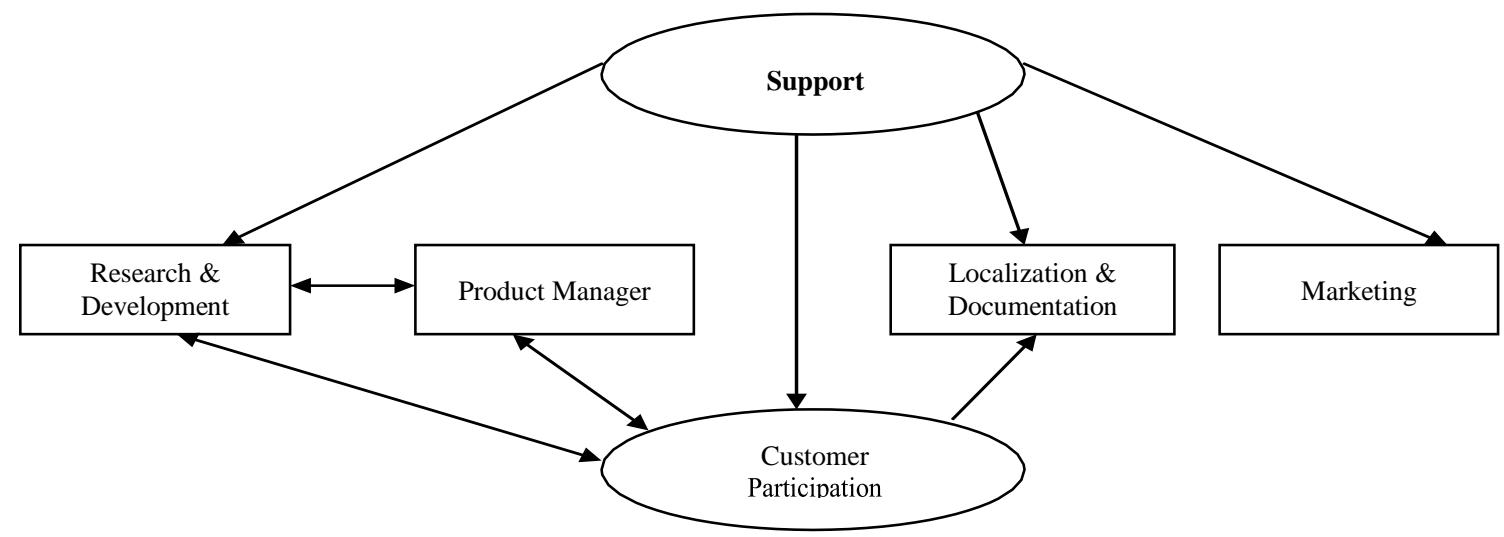

Fig. 1. User Data Communication Networks between various Company Departments.

Participants were requested to confirm their favored forms of communication. The majority preferred punchy and precise summaries or reports to set out the findings of the various tests and studies. These summaries and reports were not judged to be intriguing in themselves, but they turned out to be productive if they happened to relate clear and applicable information. The representative from product management confirmed a preference for communicating in an interactive manner, which could include events as well as more typical meetings and correspondence. As far as simple and fixed reports are concerned, the product manager expresses doubt they are always effective for communication unless some more sophisticated accompaniment is incorporated - such as being part of a presentation printout.

\section{User Involvement Actions}

According to the replies from the interviews, there are three actions that include some form of user involvement: focus groups, introspection and interviews. In doing so, all practices involved an informative or consultative form, rather than any firm participative role.

Focus groups. Intermittent market research had been carried out by the marketing manager via focus groups. This involved a group of consumers being asked to focus on the performance of a certain product or subject matter.

Conducting these groups offered crucial information on how the organization's key products are judged by those who actually utilize their capabilities. As a type of user involvement, this approach is clearly consultative in nature, as those involved have their attention focused on a particular product, concept, or service.

Introspection. Customer involvement participants confirmed that, in addition to tryout testing, employees have also looked to role play by envisioning themselves as the client, as a way of making judgments from a user's perspective. In some respects, users then become an indirect information source as part of this procedure. Consequently, this user involvement approach is clearly informative in nature.

Interviews. End users were sourced for interviews via product management in order to enhance a new product concept. This approach was judged to be an effective means for gaining firm and precise feedback via clear end user insight. Because end users were acting as an information source, user involvement is clearly informative in nature.

\section{E. Issues and Challenges}

The interviewees identified several challenges and issues during the system implementation process:

- Lack of User Data issues. As the majority of participants confirmed, the largest obstacle they face in making the mostof user involvement insights is making up for the lack of it. Indeed, some responses expressed real concern that usability as a concept is completely absent from procedures, with others confirming a desire to have robust user studies to draw upon. As previously stated, the user data available is largely made up of feedback, which alerts teams to existing issues but goes nowhere in terms of avoiding them during product development.

Sourcing user perspectives throughout early developmental periods or, preferably, as products are still in their conceptual stages, enables developers to focus on user value early on in the process, making it a part of the overall product life cycle. In contrast, when these concerns are only addressed in later stages of development, finding solutions can prove more problematic for going against the initial design, making fixes more expensive and possibly less effective. There are financial incentives as well, therefore, for end user involvement earlier in product development.

- Customer value issues. The customer involvement project manager confirmed that, at present, the organization's operations tend to be technology-led, with a commitment to addressing any issues identified rather than preventing them from occurring during design periods. This leaves us with a clear interpretation that user-centered design has yet to be fully embraced as a company priority, meaning that users' perspectives are not utilized to inform the early stages of product development.

- User interface issues. A big problem is how to judge end users' feedback when it is mixed. For example, if as many users complain about the user interface as those who compliment it. Drawing a conclusion on when to pay attention to criticism and when not is not 
easy. At the present time, it is difficult to be confident that a feature or usability solution will increase product value for users, leaving a gray area with regard to which improvements should be given priority and whether they are necessary. Furthermore, this scenario is complicated by the range of alternatives that exist on who the most important clients are and what they are like, due to a lack of user profiles. Plus, as research and development are responsible for the majority of user interfaces, they have little to go on to assess whether an interface is offering quality performance.

- Integration issues. User insight, therefore, needs to be incorporated into the current process, which, according to the product manager, needs to be achieved without relying on a separate user involvement process. If approached in any other manner, there is a real danger that aligning current processes could be problematic and have knock-on negative effects. Additionally, it might be that current development processes do not integrate with a user involvement process, meaning it will create a clear risk.

- Understanding main requirements issues. Any major implementation process needs to be made conscious of the overall company requirements; therefore, a product management participant believed that the various employees involved in such an implementation need to have a grasp of the overall company needs, as well as low-level requirements. However, in practice, the focus should be away from low-level issues in terms of establishing the overall vision, as focusing on smaller issues too early in the restructuring risks occupying developers in an unproductivemanner.

- User Feedback issues. As product development takes place, no outside feedback is currently available. This is another issue that needs to be addressed while pursuing new product visions. At the moment, tryoutstage consultation is in place but largely becomes available too late to make anything greater than small adjustments or upgrades. Gaining key information as products are in earlier developmental stages would pave the way for a more thorough approach to addressing usability issues that is cost-effective and less time-consuming over the long term. At the same time, however, better access to vital feedback alone will not answer all the problems if there are issues with current processes and workplace dynamics that remain unidentified. The localization and document technical writer indicated a number of departments from which no feedback is currently available; with no process underway to put avenues of communication in place either.

- User importance issues. The company lacks a clear means of gaining user perspectives, with the product manager raising many issues in this context. Indeed, his priority issuewas that no structured approach exists at any level within the company to facilitate reaching an understanding of client needs. Even when diligent employees strive to produce their best results, they are working without valuable insight that might enhance the efforts of even the most perceptive of developers. Plus, in the event that adeveloper does have extensive expertise on their user's requirements, there is no process in place for integrating this knowledge with the rest of the company's operations. Furthermore, current design practice is restricted to obtaining a list of key product features but without any greater conceptual design that would merge all user requirements and product objectives together.

- User interaction issues. The lack of correspondence between developers and their products' end users remains a real issue. For example, the research and development quality engineer and architect brought up a number of user involvement practice issues. In doing so, the most pressing was the absence of contact with end users in their own department, which means the communication channels are simply not open or else entirely reliant on indirect interactions. Indeed, responses can be described as passive in nature due to not being sourced with purpose or for a particular developmental context.

- User data Access issues. User perspectives are vague, muddled, and problematic to secure. One participant from customer involvement, for example, confirmed that the majority of feedback sourced tends to end up on a database or network drive, which might not be the most user friendly for research purposes and makes it difficult to find specific pieces of information. As a result, it is probably more accurate to describe such resources as data rather than as a live resource, as the information has by then been examined, given a category, and moved on from the attention of any employee. Furthermore, such databases and online resources are packed with various other reports and documents that employees will not immediately appreciate the context of just because they are readily available.

- User experience issues. Moving forward, user experience needs to be approached as integral to all company operations. Analyzing the responses of the marketing manager revealed similar issues to those raised by the technical writer, being conscious that user experience involves multiple components - not just the various software, handbooks, and packaging, but online support and Internet content too. An additional marketing issue raised was the trend of serviceoriented business operations becoming more prevalent, which comes with the necessity of understanding a great deal about end users rather than relying on habit or firmly structured approaches. Another observation the marketing manager made is that client opinions and expectations are shifting as a result of software solutions becoming merged with operating systems. Consequently, the levels of market research and user feedback required are far greater than ever before, and the current marketing operations are simply not yet equipped to handle the challenge. 


\section{DISCUSSION}

This research has explored the results of an ongoing state analysis carried out within a software house focused on developing software solutions to suit the needs of service providers, enterprises, and general consumers. A case study approach was adopted to reach our conclusions, based largely on feedback drawn from semi-structured interviews. Furthermore, this study is conducted within the context of setting up a focused group of user experience to define usercentered working practices into which all businesses may buy into. The process has included offering clarity on which user groups utilize the organization's products, the form of user information currently available from within the company, and the methods employed for communicating that information. In addition, the research explores the practices undertaken to draw feedback from users, and at the same time looks to define the most significant obstacles the company faces, with the task of enhancing its user involvement potential.

The results show how various company functions approach this challenge differently - and view end users differently - while agreement was reached on home users and service providers being the vital players. User feedback sourced via tryout tests and support products already on the market made up the most significant portion of user data available. This means processing such information is problematic due to the large quantity involved. Overall, however, the most significant issues are the lack of applicable user data, the difficulties faced in applying what information there is to working practices, and a general absence of ongoing communication with end users. To begin answering these issues, setting up a smooth and convenient means of corresponding with end users' needs to be prioritized, with the user experience team being the obvious choice for leading the way in this breakthrough.

As mentioned in Section 2, Damodaran [12] drew upon three separate forms to define user involvement: informative, consultative, and participative. From our research, it has become clear that all the available userinformation is currently either informative or consultative in nature. There are no signs of any user participation at any stage of the design process. Similar results are found when analyzing the actual user involvement practices, which were also either informative or consultative. In summation, therefore, no specific form of user participation is currently undertaken within the company.

As covered in Section II, Ives and Olson [21] established six levels to indicate stages of user involvement. As far as this research is concerned, all user participation may be defined as falling between symbolic and advisory involvement. The involvement of customers and support function have to some extent been successful in drawing customer responses, however, this is ignored owing to the lack of resources to use the information. Although there have been significant marketing focus groups and interviews carried out by product management, which does show some efficacy in terms of drawing user experiences into the company's processes, it is also clear this information is not applied to the earliest design stages, so itsimpact is limited to response only.
Muller and Czerwinski [30] identified another distinct user- centered function that is linked with product organization methods. They explain how a central group enables a company's usability experts to correspond and continually upgrade developers' working methods and vision to suit more robust final products. This approach is crucial for making sure the most skilled developers, though they may be working in isolation, are able to benefit from in-depth insights into how their work is received by and benefits others. Our own research shows a similar scenario, with the user experience professionals responsible for the whole company's user-centered services, which needs to be achieved at the same time as adhering to their own standards. Nevertheless, to realize such an effective merging of departmental priorities, there are numerous hurdles to overcome that are holding back the usabilityexperts from having a profound impact on earlier stages of development [31,32]. Currently, no clear information is obtainable regarding how well these efforts are progressing, as our focus has been on available user involvement channels as opposed to any that are in development.

The obstacles that need to be overcome in order for a successful user involvement upgrade mean a great deal of enhancement for the user experience team to carry out so that early development tasks and product visions can genuinely benefit from user feedback. One key example is that the team could begin by establishing a means of conveniently and effectively examining the available user and tryout-test feedback so that the most important issues can be highlighted and addressed. Moving forward, integrating an efficient way of obtaining and interpreting a variety of market research should be aspired to, and in a manner that makes the most of user input from the earliest design stages. At the moment, a reliance on feedback after product release shows an overreliance on technology- oriented working standards, in which responding to issues and fixing them during later developmental stages is the only means via which upgrades are achieved. It would be much better, however, to incorporate user insight from the beginning of the developmental process, because incorporating such information later on is always restricted in terms of the overall benefits that can be achieved.

\section{CONCLUSION}

This research study makes it clear that the company is too technology-oriented within its current practices. A variety of organizational factors are at play in terms of obtaining user feedback, but there is no robust method of drawing such value into overall product development. Consequently, it is hard to argue that user feedback has any kind of profound impact on product design. Although it is doubtful that having users present at an early stage would be enough to deal with this issue, the majority of participants did call for enhanced user-centered practices and objectives.

The user experience team has a vital role to play if user insight is to be made the most of throughout all levels of product design. This research offers a depth of information in terms of how this can be achieved, the enhancements thatneed to be made, and the standards that need to be adhered to. The most important aspect to take on board moving forward is that 
new methods need to be dedicated to gaining a greater comprehension of user requirements so this can be applied throughout the design stages, without undermining other standards in the process.

Looking ahead, further research should focus on the extent that the user experience team has been effective in terms of integrating themselves seamlessly with other processes and departments. Ideally, this paper will offer expertise to any practitioners keen to address similar user involvement issues, together with any who are at the stage of setting up a centralized user experience department. We also hope the conclusions drawn here are applicable for guiding future user involvement research in a number of contexts.

\section{REFERENCES}

[1] K. C. Brata, D. Liang, "An Effective Approach to Develop LocationBased Augmented Reality Information Support," International Journal of Electrical \& Computer Engineering, 2019, vol. 9, no. 4, pp. 20888708.

[2] S. D. J. Barbosa, "Investigating the Integration of User Values With Design Rationale and Its Effects on HCI Design Artifacts," Doctoral dissertation, PUC-Rio, 2020.

[3] S. Kujala, M. Kauppinen, L. Lehtola, T. Kojo, "The Role of User Involvement in Requirements Quality and Project Success," In 13th IEEE International Conference on Requirements Engineering (RE'05), pp. 75-84. IEEE, 2005.

[4] M. Bano, D. Zowghi, F. da Rimini, "User Satisfaction and System Success: An Empirical Exploration of User Involvement in Software Development," Empirical Software Engineering, 2017, vol. 22, no.5, pp. 2339-2372.

[5] U. Abelein, B. Paech, "Understanding the Influence of User Participation and Involvement on System Success - A Systematic Mapping Study," Empirical Software Engineering, 2015, vol. 20, no. 1, pp.28-81. doi: 10.1007/s10664-013-9278-4.

[6] P. Mohagheghi, M. Jorgensen, "What Contributes to the Success of IT Projects? Success Factors, Challenges and Lessons Learned from an Empirical Study of Software Projects in the Norwegian Public Sector," IEEE/ACM 39th International Conference on Software Engineering Companion (ICSE-C), 2017, pp. 371-3.

[7] M. Bano, D. Zowghi, F. Rimini, "User Satisfaction and System Success: An Empirical Exploration of User Involvement in Software Development," Empirical Software Engineering, 2017, vol. 22, no.5, pp.2339-72. doi: 10.1007/s10664-016-9465-1.

[8] K. Siakas, E. Georgiadou, D. Siakas, "The Future of the IT Department: Is There a Threat by End User Application?" The Cyprus Journal of Sciences, 2017, vol. 15, pp. 63-82.

[9] T. Issa, P. Isaias, "User Participation in the System Development Process," Sustainable Design, 2015, pp. 37-57.

[10] A. M. Baronas, R. Louis, "Restoring a Sense of Control During Implementation: How User Involvement Leads to System Acceptance," Management Information Systems Quarterly, 1988, vol. 12, no.1: pp. 111-123.

[11] T. H. Kwon, R. W. Zmud, "Unifying the Fragmented Models of Information Systems Implementation," In Boland, R. J. \& Hirschheim, R. A. (Eds.), Critical Issues in Information Systems Research, John Wiley, New York, 1987.

[12] L. Damodaran, "User Involvement in the Systems Design Process - A Practical Guide for Users," Behaviour \& information technology, 1996, vol. 15 , no. 6, pp.363-377.

[13] K. K. O. Tha, "Developing a Framework for User Participation in Information System Development Projects," Paper presented at the 25th Americas Conference on Information Systems. (2019).
[14] J. Klemets, T. C. B. Storholmen, "Towards Super User-Centred Continuous Delivery: A Case Study," In International Conference on Human-Centred Software Engineering, 2020, pp. 152-165, Springer, Cham.

[15] K. Redlarski, P. Weichbroth, "Hard Lessons Learned: Delivering Usability in IT Projects," In 2016 Federated Conference on Computer Science and Information Systems (FedCSIS), pp. 1379-1382, IEEE, 2016.

[16] J. M. Noyes, A. F. Starr, \& C. R. Frankish, "User Involvement in the Early Stages of the Development of an Aircraft Warning System," Behaviour \& Information Technology, 15, 2, 67-75. 1996.

[17] M. Bano, D. Zowghi, "A Systematic Review on the Relationship Between User Involvement and System Success," Information and Software Technology, 2015, vol. 58, pp. 148-169.

[18] S. Kujala, "User Involvement: A Review of the Benefits and Challenges," Behaviour \& Information Technology, 2003, vol. 22, no.1, pp. 1-16.

[19] M. Bano, \& D. Zowghi, "User Involvement in Software Development and System Success: A Systematic Literature Review,". In Proceedings of the 17th International Conference on Evaluation and Assessment in Software Engineering (pp. 125-130). New York: ACM, 2013.

[20] J. Simonsen, \& T. Robertson, (Eds.). "Routledge International Handbook of Participatory Design,". London: Routledge. 2013.

[21] ISO 9241-210: 2010. Ergonomics of Human-System Interaction - Part 210: Human-Centered Design for Interactive Systems, 2010. https://www.iso.org/standard/52075.html.

[22] Z. Taha, H. Alli \& S. H. Abdul-Rashid, "The characteristics of a new product through user knowledge in the early stages of a design process,". Journal of Advanced Materials Research, vol. 739, pp. 678683. 2013.

[23] J. Janhager, "User consideration in early stages of Product Development: Theories and methods,". Stockholm: PhD Thesis, Royal Institute of Technology. 2005.

[24] Z. Taha, H. Alli, \& S. H. Abdul-Rashid, "User's requirement and preference in the success of a new product: A case study of automotive design,". Journal of Applied Mechanics and Materials, vol. 215, pp.484488. 2012. Trans Tech Publications Ltd.

[25] H. Alli, "User involvement method in the early stage of new product development process for successful product,". Alam Cipta: International Journal of Sustainable Tropical Design Research and Practice, 11(1), 2328. 2018.

[26] M. E. A. Webber, M. Weggeman, \& J. E. van Aken, "Developing what customers really need: Involving customers in innovations,". International Journal of Innovation and Technology Management, vol. 9, no. 3, pp. 1-15. 2010.

[27] B. Ives, M. Olson, "User Involvement and MIS Success: A Review of Research,". Management Science, vol. 30, no. 5, pp586-603. 1984.

[28] R. Yin, Case Study Research - Design and Methods. Sage Publications, 2003.

[29] N. King, C. Cassell, and G. Symon, "Using templates in the thematic analysis of text. Essential guide to qualitative methods in organizational research," 2004. Vol. 2, pp. 256-70.

[30] M. Muller, M. Czerwinski, "Organizing Usability Work to Fit the Full Product Range,". Communications of the ACM, 1999, vol. 42, no. 5, pp. 87-90.

[31] N. Anjum, M. Sarker, S. I. Ahmed, "Evaluation of Web Usability Requirement Model and Web Application Interface Components. Evaluation, 2018.

[32] W. Wang, J. Cheng, J. L. Guo, "How Do Open Source Software Contributors Perceive and Address Usability? Valued Factors, Practices, and Challenges,". IEEE Software, 2020. 